\title{
KEGIATAN PENYULUHAN PADA REMAJA TENTANG PERSONAL HYGIENE DAN PUBERTAS DI KAMPUNG PAMEUNGPEUK DESA CIKUNIR KECAMATAN SINGAPARNA TASIKMALAYA TAHUN 2018
}

\author{
OLEH : \\ HAPI APRIASIH, S.ST,M.Kes \\ (py.anbyan@gmail.com) \\ TUPRILIANY DANEFI, S.ST,M.Kes \\ (tuprilianydanefi07@gmail.com)
}

\section{A. DASAR PEMIKIRAN}

Seiring dengan perkembangan zaman, masalah remaja makin bertambah di mana-mana khususnya di Indonesia. Masa remaja adalah masa peralihan dari masa anak-anak ke masa dewasa. Masalah remaja di zaman ini bukanlah baru terjadi, tapi dari tahun sebelum-sebelumnya sudah sering terjadi, dimana masalah pada remaja yaitu pergaulan bebas, tawuran, memakai narkoba, menonton film porno, meminum minuman alkohol, pesta pora dan masih banyak lagi masalah yang terjadi pada remaja. Dan sekarang ini ada juga anakanak yang masih duduk di bangku sekolah seperti SD, maupun SMP dan SMA sudah ada yang merokok, pergaulan bebas, meminum alkohol, menonton film porno, dan bahkan ada yang sudah hamil di luar nikah. Ini semua terjadi karena kurang adanya pengawasan dari orangtua atau keluarga, guru, dan pemerintah. Masalah remaja tentunya tak jarang lagi mendengar atau menonton dan bahkan melihat yang terjadi disekitar kita.

Berdasarkan hasil Survei Kesehatan berbasis Sekolah di Indonesia tahun 2015 (GSHS) dapat terlihat gambaran faktor risiko kesehatan pada pelajar uisa 12-18 tahun secara nasional sebanyak 41,8 \% lakilaki dan $4,1 \%$ perempuan mengaku pernah merokok, 32,82 \% doantara merokok pertama kali pada umur $<13$ tahun. Gambaran faktor resiko kesehatan lainnya adalah perilaku seksual dimana didapatkan
$8,26 \%$ pelajara laki-laki dan 4,17 pelajara perempuan usia 12-18 tahun pernah melakukan hubungan seksual.

Perilaku seks pranikah tentunya memberikan dampak yang luas pada remaja terutama berkaitan dengan penularan penyakit dan kehamilan yang tidak diinginkan serta aborsi. Kehamilan pada remaja tidak hanya berpengaruh terhadap kondisi fisik, mental dan sosial remaja tetapi juga meningkatkan resiko kematian bayi dan balita, seperti yang ditunjukkan SDKI 2012 dimana kehamilan dan persalinan pada ibu dibawah umur 20 tahun memiliki kontribusi dalam tingginya Neonatal Mortality Rate (34/1000 KH), Postnatal Mortality Rate $(16 / 1000 \mathrm{KH})$, Infant Mortality Rate (50/1000 KH) dan under -5 Mortality Rate (61/1000 KH). Laporan triwulan Direktorat Jenderal Pengendalian Penyakit dan Penyehatan Lingkungan (Ditjen P2PL) mulai 1987 sampai dengan Maret 2017 menunjukkan bahwa tingginya angka kejadian AIDS di kelompok usia 20-29 tahun mengindikasikan kelompok tersebut pertama kali terkena HIV pada usia remaja.

Di Desa Cikunir merupakan desa di wilayah Puskesmas Singaparna yang terdiri dari 3 dusun yaitu Gunung Kawung, Pameungpeuk, dan Anggaraja. Melalui kegiatan praktik kerja nyata mahasiswa Program Studi Kebidanan STIKes Respati Tasikmalaya melalui focus grup discucion (FGD) diperoleh informasi dari 35 responden remaja sebagai berikut $48,7 \%$ 
belum mengetahui kesehatan reproduksi khususnya terkait infeksi menular seksual, $45,71 \%$ sudah mempunyai pcar, 51,43\% tidak mengetahui tentang HIV/AIDS, $22,86 \%$ tidak mengetahui dampai pernikahan dini, dan $11,43 \%$ setuju dengan pernikahan dini.

Berdasarkan data tersebut diketahui bahwa pengetahuan remaja tentang kesehatan reproduksi remaja masih kurang dan akan berdampak pada permasalahan yang serius maka menjadi hal yang sangat penting untuk adanya upaya dalam hal peningkatan pengetahuan remaja, oleh karena diselenggarakan kegiatan penyuluhan tentang personal higyene dan masa pubertas pada remaja.

\section{B. TUJUAN}

Adapun tujuan dari kegiatan ini adalah
1. Meningkatkan pengetahuan remaja tentang personal higyene dan masa pubertas pada remaja

2. Meningkatkan pengetahuan remaja tentang masa pubertas pada remaja.

\section{SASARAN}

Kegiatan pendidikan kesehatan (penyuluhan) kesehatan mengenai personal hygiene dan masa pubertas pada remaja ditujukan pada remaja usia 12 sampai 21 tahun di kampung pameungpeuk Desa Cikunir Kabupaten Tasikmalaya

\section{WAKTU DAN TEMPAT PELAKSANAAN}

Kegiatan dilakukan dari tanggal 26 september 2018, bertempat di Kp Pameungpeuk Desa Cikunir Kec Singaparna Kab Tasikmalaya.

\section{E. HASIL KEGIATAN}

Adapun pelaksanaan kegiatan yang dilakukan sebagai berikut:

1. Persiapan
a. Dilakukan survey sasaran dengan melibatkan kader setempat
b. Pengurusan ijin
c. Pengurusan administrasi (surat menyurat)
d. Persiapan alat dan bahan serta akomodasi
e. Persiapan tempat yaitu di posyandu kp pameungpek

2. Pelaksanaan kegiatan penyuluhan

a. Pembukaan dan Perkenalan dari mahasiswa kepada peserta

b. Penyuluhan kepada remaja tentang personal hygiene dan masa pubertas pada remaja

c. Sesi diskusi dan Tanya jawab kepada peserta

3. Penutupan

a. Pemberian door prize bagi peserta yang mampu menjawab pertanyaan

b. Foto bersama dengan peserta penyuluhan

c. Berpamitan dengan pengurus dan peserta

d. Pembuatan laporan kegiatan pengabdian masyarakat

\section{Output}

Output yang didapat dari kegiatan pengabdian masyarakat ini diantaranya adalah :

a. Remaja diberikan pendidikan kesehatan (penyuluhan) mengenai pengertian personal hygiene dan bagaimana cara menjaga kebersihan diri pada saat menstruasi khusus untuk remaja putri serta penyuluhan tentang masa pubertas pada remaja meliputi tentang pengertian pubertas, tanda-tanda puberta, tips memasuki masa pubertas 
b. Dari hasil penyuluhan, remaja memahami mengenai isi materi dan di akhir sesi diberikan waktu tanya jawab. Didapatkan beberapa pertanyaan dari remaja diantaranya : a. Bagaimanakah cara menghadapi masa pubertas dengan baik $b$. hal yang harus dilakukan remaja putri pada saat menghadapi menstruasi?

c. Untuk mengevaluasi tingkat pemahaman remaja terhadap isi materi penyuluhan, maka diberikan beberapa pertanyaan terkait isi materi penyuluhan dan remaja dipersilahkan untuk menjawab. remaja yang berhasil menjawab pertanyaan dengan benar diberikan door prize sebagai tanda apresiasi.

\section{Outcome}

Outcome yang didapatkan diantaranya adalah :

a. Dengan adanya program pengabdian masyarakat yang berupa penyuluhan mengenai personal hygiene dan masa pubertas pada remaja ini diharapkan dapat meningkatkan pengetahuan remaja tentang personal hygiene dan masa pubertas pada remaja., selain itu diharapkan semakin meningkatkan kesadaran remaja tentang pentingnya bagaimana menghadapi masa pubertas dan bagi remaja putri dapat menjaga personal hygiene pada saat menstruasi.

b. Diharapkan kegiatan serupa dapat berdampak pada peningkatan kesadaran masyarakat Indonesia khususnya pada remaja sebagai generasi muda agar ikut aktif menjaga personal hygiene dan memahami bagaimana menghadapi masa pubertas dengan baik.

c. Diharapkan STIKes Respati semakin dikenal dan terdepan dalam membantu dalam meningkatkan kepedulian terhadap permasalahan masyarakat khususnya generasi muda yang ada di wilayah Kabupaten Tasikmalaya.

\section{F. DAFTAR PUSTAKA}

Badan Litbangkes. Laporan Penelitian Survey Kesehatan Berbasis Sekolah di Depok Jawa Barat pada sekolah tingkat SMP. Jakarta:Kementrian Kesehatan; 2006

PUSLITBANG Upaya Kesehatan Masyarakat Badan LITBANKES KEMENKES RI . Perilaku Beresiko Kesehatan Pada Pelajar SMP dan SMA. Jakarta: Hasil Survey Nasional Kesehatan Berbasis Sekolah di Indonesia; 2015

Survey Demografi dan Kesehatan Indonesia (SDKI). 2012. Angka Kematian Ibu. Dikutip dari www.bkkbn.co.id diakses pada tanggal 20 September 2018. 


\section{G. DOKUMENTASI KEGIATAN}
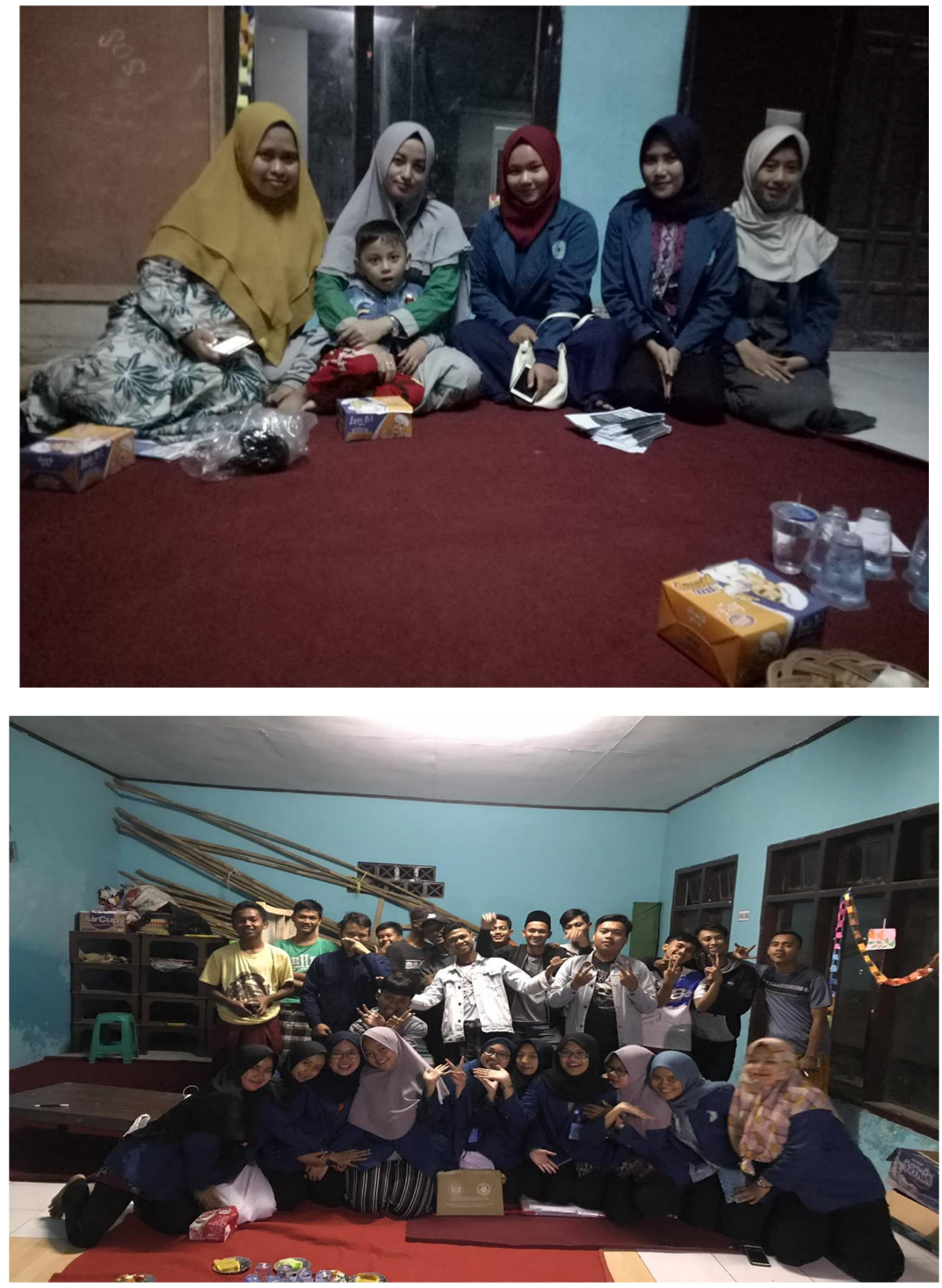

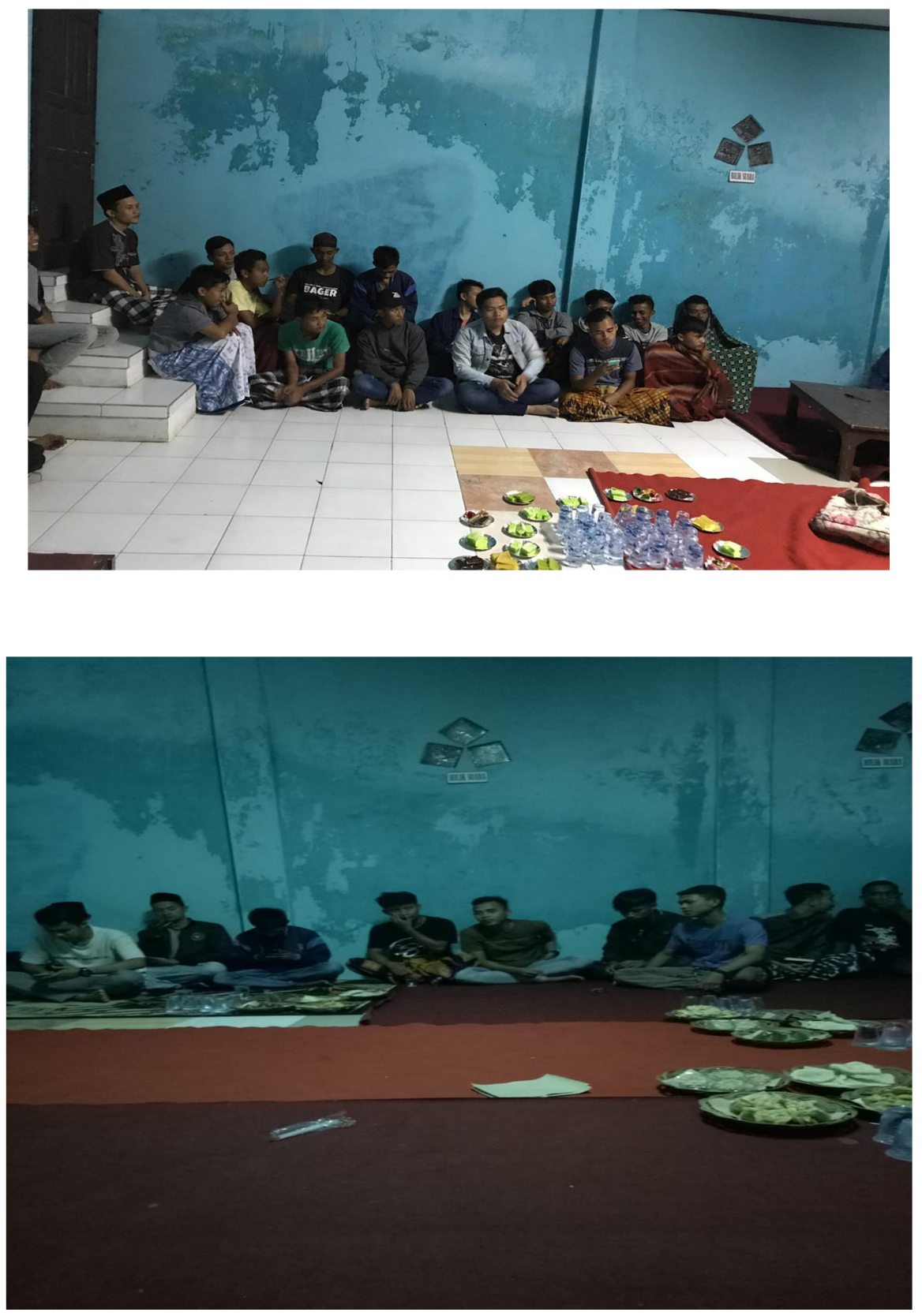